\title{
Graft considerations for successful anterior cruciate ligament reconstruction
}

Hee-Soo Kyung

For successful anterior cruciate ligament (ACL) reconstruction, several factors, such as preoperative planning, operation technique, and postoperative rehabilitation, have to be considered [1, 2]. Graft choice, fixation, preparation method, maturation, incorporation to host bone, and graft tension should also be considered for good outcome after ACL reconstruction [2]. Several autografts, including the bone-patellar tendon-bone (BTB), hamstring tendon (HT), and quadriceps tendon-bone (QT-B), have been introduced. However, each has its own advantages and disadvantages [3].

The theme of this issue of Knee Surgery \& Related Research is the preparation method of HT autograft and the evaluation of the graft maturation in ACL reconstruction. Graft preparation for the HT during ACL reconstruction can be performed by several methods, mostly quadruple semitendinosus \& gracilis (ST\&G), triple ST\&G, and quadruple ST [3, 4]. Adequate graft length and diameter are very important for good graft preparation. Adequate graft length is important for early fixation strength in bone tunnel and then for accelerated rehabilitation, so it is usually recommended to be over $7 \mathrm{~cm}$ [4]. The graft diameter, which affects the graft re-rupture rate, is usually recommended to be over $7 \mathrm{~mm}[5,6]$.

Dr. Goyal's report about HT graft preparation is a very interesting article. They compared weave graft and parallel graft preparations to make graft length over $8 \mathrm{~cm}$ and graft diameter 7 10 $\mathrm{mm}$. Weave preparation of threestrand ST could be made thicker in diameter, which reduced the gracilis harvesting compared with the parallel graft. Weave graft preparation did not compromise functional outcome and seems to have better graft re-rupture rate 2 years after the operation. So the authors expected preserving the strength in deep flexion and internal rotation of tibia through preserving the gracilis tendon.

Another report about ACL reconstruction, by Dr. Kim, is a systematic review related to evaluation methods of graft maturation on second-look arthroscopy in which
28 studies were analyzed. Graft integrity, tension, and synovial coverage were most frequently evaluated for graft maturation on second-look arthroscopy. Although a few studies reported that the graft tension was significantly correlated with objective stability, second-look findings seem to be less correlated to the clinical outcomes [7-9]. Graft integrity and synovial coverage had no correlation with stability in the included studies [7-10]. There was also no correlation between second-look findings and patient-reported outcomes $[7,9,11]$. Kim et al. concluded that these results may be due to the subjective evaluation of the second-look arthroscopy and the limitations of using evaluation methods that have not yet been validated.

The recent increased use of allograft for ACL reconstruction is due to no donor site morbidity, decreased surgical time, diminished postoperative pain, and good availability of source [12]. However, there were no reports that suggest that allograft may have a better longterm outcome than autograft. Allografts have inherent disadvantages, including a longer and less complete course of incorporation, remodeling, biomechanical inferiority to autograft, and the potential risk of immunogenic reaction and disease transmission [13, 14]. Allograft remodeling is delayed in ACL reconstruction and results in reduced long-term stability and mechanical function compared with autograft ACL reconstruction [13, 14]. Higher longterm failure rates and poorer graft maturation score for allograft were reported compared with those for autograft $[15,16]$. The autograft in ACL reconstruction should remain the gold standard, although the allograft is a reasonable alternative.

If adequate length and diameter of autograft can be obtained for ACL reconstruction, autograft with adequate graft fixation and postoperative rehabilitation should be chosen instead of allograft to expect better results. Every effort to enhancing graft maturation and to make a strong graft should be made for a better outcome after ACL reconstruction. 


\section{Abbreviations}

ACL: Anterior cruciate ligament; HT: Hamstring tendon; ST\&G: Semitendinosus \& gracilis

\section{Acknowledgments}

Not for Editorial.

\section{Funding}

No external funding was used.

\section{Availability of data and materials}

Not for Editorial.

\section{Authors' contributions}

The author read and approved the final manuscript.

\section{Competing interests}

The author declares that he has no competing interests.

\section{Publisher's Note}

Springer Nature remains neutral with regard to jurisdictional claims in published maps and institutional affiliations.

Received: 8 May 2019 Accepted: 14 May 2019

Published online: 28 June 2019

\section{References}

1. Ansari MH, Claes S, Wascher DC, Neyret P, Stuart MJ, Krych AJ (2017) International perspective on revision anterior cruciate ligament reconstruction: What have we been missing? Instr Course Lect. 66:543-556

2. Harner CD, Giffin JR, Dunteman RC, Annunziata CC, Friedman MJ (2001) Evaluation and treatment of recurrent instability after anterior cruciate ligament reconstruction. Instr Course Lect. 50:463-474

3. Fu F, Christel P, Miller MD, Johnson DL (2009) Graft selection for anterior cruciate ligament reconstruction. Instr Course Lect. 58:337-354

4. Kyung HS, Lee HJ, Oh CW, Hong HP (2015) Comparison of results after anterior cruciate ligament reconstruction using a four-strand single semitendinosus or a semitendinosus and gracilis tendon. Knee Surg Sports Traumatol Arthrosc. 23:3238-3243

5. Spragg L, Chen J, Mirzayan R, Love R, Maletis G (2016) The effect of autologous hamstring graft diameter on the likelihood for revision of anterior cruciate ligament reconstruction. Am J Sports Med. 44:1475-1481

6. Magnussen RA, Lawrence JT, West RL, Toth AP, Taylor DC, Garrett WE (2012) Graft size and patient age are predictors of early revision after anterior cruciate ligament reconstruction with hamstring autograft. Arthroscopy 28:526-531

7. Nakamae A, Ochi M, Deie M, Adachi N, Shibuya H, Ohkawa S et al (2014) Clinical outcomes of second-look arthroscopic evaluation after anterior cruciate ligament augmentation: Comparison with single- and double-bundle reconstruction. Bone Joint J. 96-B:1325-1332

8. Tanaka Y, Shino K, Horibe S, Nakamura N, Nakagawa S, Mae T et al (2012) Triple-bundle acl grafts evaluated by second-look arthroscopy. Knee Surg Sports Traumatol Arthrosc. 20:95-101

9. Ahn JH, Yoo JC, Yang HS, Kim JH, Wang JH (2007) Second-look arthroscopic findings of 208 patients after acl reconstruction. Knee Surg Sports Traumatol Arthrosc. 15:242-248

10. Toritsuka Y, Shino K, Horibe S, Mitsuoka T, Hamada M, Nakata K et al (2004) Second-look arthroscopy of anterior cruciate ligament grafts with multistranded hamstring tendons. Arthroscopy 20:287-293

11. Kondo E, Yasuda K (2007) Second-look arthroscopic evaluations of anatomic double-bundle anterior cruciate ligament reconstruction: Relation with postoperative knee stability. Arthroscopy 23:1198-1209

12. Tisherman R, Wilson K, Horvath A, Byrne K, De Groot J, Musahl V (2019) Allograft for knee ligament surgery: An american perspective. Knee Surg Sports Traumatol Arthrosc. 27:1882-1890. https://doi.org/10.1007/s00167-019-05425-2 [Epub ahead of print]

13. Hulet C, Sonnery-Cottet B, Stevenson C, Samuelsson K, Laver L, Zdanowicz U et al (2019) The use of allograft tendons in primary acl reconstruction. Knee Surg Sports Traumatol Arthrosc. 27:1754-1770. https://doi.org/10.1007/s00167-01905440-3 Epub ahead of print
14. Nissen KA, Eysturoy NH, Nielsen TG, Lind M (2018) Allograft use results in higher re-revision rate for revision anterior cruciate ligament reconstruction Orthop J Sports Med. 6:2325967118775381

15. Bottoni CR, Smith EL, Shaha J, Shaha SS, Raybin SG, Tokish JM et al (2015) Autograft versus allograft anterior cruciate ligament reconstruction: A prospective, randomized clinical study with a minimum 10-year follow-up. Am J Sports Med. 43:2501-2509

16. Kim SG, Kim SH, Kim JG, Jang KM, Lim HC, Bae JH (2018) Hamstring autograft maturation is superior to tibialis allograft following anatomic single-bundle anterior cruciate ligament reconstruction. Knee Surg Sports Traumatol Arthrosc. 26:1281-1287

\section{Ready to submit your research? Choose BMC and benefit from:}

- fast, convenient online submission

- thorough peer review by experienced researchers in your field

- rapid publication on acceptance

- support for research data, including large and complex data types

- gold Open Access which fosters wider collaboration and increased citations

- maximum visibility for your research: over $100 \mathrm{M}$ website views per year

At BMC, research is always in progress.

Learn more biomedcentral.com/submissions 